\title{
Stress Study on CrN Thin Films with Different Thicknesses on Stainless Steel
}

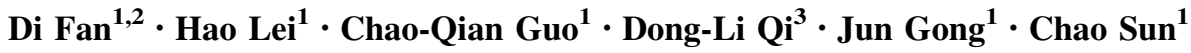

Received: 24 April 2017/Revised: 21 May 2017/Published online: 7 July 2017

(C) The Chinese Society for Metals and Springer-Verlag GmbH Germany 2017

\begin{abstract}
The reliability of a substrate curvature-based stress measurement method for $\mathrm{CrN}$ thin films on substrate with fluctuant surface was discussed. The stress error led by the ignorance of substrate thermal deformation was studied. Results showed that this error could be as large as several hundred MPa under general deposition conditions. Stress in the CrN thin films with different thicknesses ranging from 110 to $330 \mathrm{~nm}$ on stainless steel was studied by this method, in comparison with conventional results on silicon wafer. The thin films' morphology and structure were investigated and related to the film stress. A significant result of the comparison is that stress evolution in the thin films on steel obviously differs from that on silicon wafer, not only because the two substrates have different coefficients of thermal expansion, which provokes thermal stress, but also the considerable discrepancy in the thin films' grain coarsening rate and structure that induce different intrinsic stresses.
\end{abstract}

KEY WORDS: Stress; CrN film; Magnetron sputtering; Stoney equation; Steel substrate

\section{Introduction}

Chromium nitride coatings have been widely used in wear and corrosion industries for nearly three decades. Their excellent mechanical properties and corrosion resistance due to the passivating oxide layer formed on surface make the film series not only a well-established independent

Available online at http://link.springer.com/journal/40195

Hao Lei

haolei@imr.ac.cn

$\triangle$ Chao Sun

csun@imr.ac.cn

1 Institute of Metal Research, Chinese Academy of Sciences, Shenyang 110016, China

2 University of Chinese Academy of Sciences, Beijing 100049, China

3 School of Science, Shenyang Ligong University, Shenyang 110159, China protective coating, but also a desirable supplement to its counterpart in composite structures, such as CrN-based multilayers $[1,2]$.

In multilayer systems, $\mathrm{CrN}$ monolayer with small thickness improves toughness and guarantees hardness simultaneously, and the studies of monolayer $\mathrm{CrN}$ thin films have been elaborated from many different angles [3-5]. Among them, intrinsic stress evolution across film thickness triggered much interests, since it is one of the key elements that influence on other mechanical properties as well as the design of multilayer structure. Noveau et al. [6] and Djouadi et al. [7] deposited CrN films at relatively low temperatures without substrate bias and observed a peak of compressive stress which appeared at a given thickness of 150-200 nm. Janssen et al. [8] found the compressive stress in $\mathrm{CrN}$ coatings deposited at $450{ }^{\circ} \mathrm{C}$ with a bias of $175 \mathrm{~V}$ monotonously increased with the film thickness, while Daniel et al. [9] argued both the intrinsic and thermal stresses were thickness dependent and the compressive stress in $\mathrm{CrN}$ films deposited at $350{ }^{\circ} \mathrm{C}$ decreased as the thickness increased from 100 to $1000 \mathrm{~nm}$. Though the 
stress value and evolution trend of $\mathrm{CrN}$ films remained controversial issues in different studies due to the diverse deposition parameters, the origination of intrinsic stress is thoroughly analyzed and mostly based on the VolmerWeber growth mechanism [10]. Microstructure, which naturally relates to the film thickness, contributes in various ways to the generation of intrinsic stress. The initial compressive stress was attributed to the isolated crystallite islands with compressive surface stress acting on the substrate surface [11], and then the process of islands coalescence made the clusters contact and interact, resulted in the generation of tensile stress [12]. During the deposition under relatively high temperature, diffusion of excess sputtered adatoms to the grain boundaries that reduced their free energy also gave rise to the development of compressive stress [13].

Although the thickness and microstructure-dependent stress evolution of $\mathrm{CrN}$ thin films has been discussed in detail, it is noteworthy that these results were revealed through a series stress tests conducted on films growing on silicon wafer, rather than real substrate for protective coatings in application. It is well known that film stress varies obviously with substrate, considering not only their different coefficients of thermal expansion but also surface status [14]. In terms of protective coatings in our case, it is inappropriate to correlate the mechanical properties of films growing on tool substrate to stress of films measured on silicon wafer. Studying the residual stress in $\mathrm{CrN}$ thin films with different thicknesses deposited on tool substrate like stainless steel is undoubtedly more meaningful from the perspective of industrial application.

Among various kinds of stress measurement methods for thin films, substrate curvature technique (SCT) based on Stoney formula $[15,16]$,

$\sigma=-\frac{E_{\mathrm{s}} h_{\mathrm{s}}^{2}}{6\left(1-\vartheta_{\mathrm{s}}\right) h_{\mathrm{f}}}\left(\frac{1}{R_{2}}-\frac{1}{R_{1}}\right)$,

with $\sigma$ the in-plane stress in the film, $E_{\mathrm{s}}$ Young's modulus of the substrate, $\vartheta_{\mathrm{s}}$ Poisson's ratio for the substrate (AISI 304 [17]: $E_{\text {steel }}=180.5 \mathrm{GPa}, \vartheta_{\text {steel }}=0.3, \mathrm{Si}$ (001) [18]: $\left.E_{\mathrm{Si}}=130 \mathrm{GPa}, \vartheta_{\mathrm{Si}}=0.28\right), h_{\mathrm{s}}$ thickness of the substrate, $h_{\mathrm{f}}$ thickness of the film and $R_{1} / R_{2}$ the radius of curvature of the substrate before/after deposition of the thin film, still remains the first choice, given the fact that the usually unknown elastic moduli of film are an indispensable parameter and the inevitable influence caused by the film thickness and texture when using X-ray diffraction $\sin 2 \psi$ technique to evaluate residual stress [19]. Our previous work proposed a SCT method based on the measurement of sample movement distance $D$ and laser spot movement distance $L$, and the following equation was employed to calculate the substrate curvature,
$R=\frac{2 H}{\partial D / \partial L}$,

with $H$ a device dependent constant [20]. In this study, two problems need to be tackled when extending $D-L$ method to $\mathrm{CrN}$ thin film-stainless steel substrate system are addressed: (1) SCT is based on the precondition that the substrate has a regularly arc surface, whose $D-L$ curves before and after deposition should be straight lines with constant slopes that make the curvature calculation possible, while some steel strips have fluctuant surface, which produces nonlinear $D-L$ curves. The fluctuation could be ignored if the stress causes comparatively large curvature change in the substrate after film deposition, like the situation in Stoney's first paper on Stoney equation [16] and the stripping experiment by Zhao et al. [20]. But when a monolayer film with small thickness is studied, the substrate fluctuation becomes an obstacle in the way of deriving the curvature. Figuring out an approach to calculate film stress without the uniform $R$ value for substrate becomes the first priority in this work. (2) It is a long neglected fact that the curvature of tool substrate with a large amount of machining defects changes with not only the generation of film stress but also the annealing process for the substrate itself during deposition, especially when the film is fabricated under high temperature. As far as we know, no literature concerned with stress of films on tool substrate has mentioned the defect elimination process for substrate before film deposition. In this work, the stress error led by the ignorance of substrate deformation due to high deposition temperature would be calculated and the proper heat-treatment procedure that avoids the stress error would be proposed.

\section{Experimental}

\subsection{Heat Treatment for Stainless Steel Strip}

To simulate the annealing process for substrates during film deposition, three sets of mirror-polished $0 \mathrm{Cr} 18 \mathrm{Ni} 9$ stainless steel (AISI 304) strips in size of $10 \mathrm{~mm} \times 40 \mathrm{~mm}$ with thickness of $0.5,0.8$ and $2 \mathrm{~mm}$ were adopted as samples for heat-treatment test. The steel strips were put into vacuumed quartz tubes with pressure lower than $7 \times 10^{-3} \mathrm{~Pa}$ and successively annealed at five different temperatures, i.e., $100,200,300,400$ and $500{ }^{\circ} \mathrm{C}$, in a muffle furnace. Each annealing procedure lasts for $3 \mathrm{~h}$, and the $D-L$ tests were conducted before and after every heattreatment stage. This process was then repeated to ensure the 3 -h heat treatment at $500{ }^{\circ} \mathrm{C}$ is effective to avoid stress error. 


\subsection{Preparation of the CrN Thin Films}

A set of five $\mathrm{CrN}$ films with different thicknesses were deposited by a JGP560 magnetron sputtering system. The apparatus has a water-cooled disk targets $\mathrm{Cr}$ (in size of $\varphi$ $70 \mathrm{~mm} \times 6 \mathrm{~mm}$ ) with $99.9 \%$ purity connected to DC Power. Permanent magnets are placed at the back of the target to maintain the plasma. Mirror-polished steel strips in size of $40 \mathrm{~mm} \times 10 \mathrm{~mm} \times 0.3 \mathrm{~mm}$ were adopted as substrate for film deposition, as the thicker substrate showed trivial deflection which is hard to detect. After being ultrasonically cleaned in acetone and ethanol for 20 min together with a Si wafer with (001) orientation in the same size, all the substrates were dried and mounted to a holder which is $5.5 \mathrm{~cm}$ to the targets and equipped with a heater. The heater started to increase the substrate temperature when the chamber was vacuumed to $5 \times 10^{-3} \mathrm{~Pa}$ and then maintained the temperature at $500{ }^{\circ} \mathrm{C}$ during the deposition process. Gas was introduced to the system when chamber pressure reached $5 \times 10^{-4} \mathrm{~Pa}$. Pure argon (Ar, purity $99.999 \%)$ and pure nitrogen $\left(\mathrm{N}_{2}\right.$, purity $\left.99.999 \%\right)$ were working gas for the $\mathrm{CrN}$ thin film deposition, and the specific deposition parameters are shown in Table 1.

\subsection{Measurement of $D-L$ Curves}

The $D-L$ curves of films were measured by film stress tester (FST 150, SPI, China) [21], and test length was set to be $25 \mathrm{~cm}$. $D-L$ tests were conducted for each sample before and after heat treatment or film deposition, and the average value of experimental data from four tests was adopted to generate the $D-L$ curves.

\subsection{Film Characterization}

Scanning electron microscope (SEM; S-3400 N, Hitachi, Japan) was carried out to characterize the thickness of the films. Atomic force microscope (AFM; Pico Scan 2500, Agilent Technologies, USA) in contact mode was used to capture the surface images of the films and calculate the grain circumference. For films on silicon and steel substrates, the AFM scan size was 2 and $1 \mu \mathrm{m}$, respectively. Transmission electron microscope (TEM; JEM-2100F, JEOL, Japan) was used to observe the cross-sectional morphology of the films.

\section{Results and Discussion}

\subsection{Nominal $D-L$ Curve Method for Stress Calculation}

Figure 1 shows the typical $D-L$ linear curves for regularly arc Si wafer and steel strips with fluctuant surface. As is shown in the dashed box of Fig. 1b, for steel substrate, the curvature radius is not uniform at positions $a$ and $b$. We make an assumption that the film stress is identical through the sample, i.e.,

$\sigma_{a}=\sigma_{b}$.

According to Eqs. (1)-(3), we can derive

$\frac{\partial D_{a 2}}{\partial L_{a 2}}-\frac{\partial D_{a 1}}{\partial L_{a 1}}=\frac{\partial D_{b 2}}{\partial L_{b 2}}-\frac{\partial D_{b 1}}{\partial L_{b 1}}$,

We define a nominal slope,

$K_{n}=\frac{\partial D_{n 2}}{\partial L_{n 2}}-\frac{\partial D_{n 1}}{\partial L_{n 1}}=\frac{\Delta\left(D_{n 2}-D_{n 1}\right)}{L_{n}}$,

which represents the slope of the subtraction curve from the original nonlinear $D-L$ curves.

A linear subtraction $D-L$ curve whose slope is a constant value shown in the lower part of Fig. 1b indicates the correctness of our assumption. We define the subtraction curve as nominal $D-L$ curve, and the identical stress in different segments of the film deposited on a fluctuant surface could be calculated with the following formula derived from Eqs. (1) to (5),

$\sigma=-\frac{E_{\mathrm{s}} h^{2} K_{n}}{12 H\left(1-\vartheta_{\mathrm{s}}\right) h_{\mathrm{f}}}$.

The stress error brought in by the curvature change of substrate due to high-temperature deposition could also be calculated by this equation.

\subsection{Stress Error Analysis}

$D-L$ curves for stainless steel strip with thickness of $2 \mathrm{~mm}$ show no obvious change after annealing, indicating that the thick substrate did not produce any traceable deflection under the deposition temperature, while for strips with thickness of 0.5 and $0.8 \mathrm{~mm}, D-L$ curves changed dramatically before and after heat treatment, and their nominal

Table 1 Deposition parameters of the $\mathrm{CrN}$ thin films

\begin{tabular}{|c|c|c|c|c|c|c|c|c|c|}
\hline \multirow[t]{2}{*}{ Voltage (V) } & \multirow[t]{2}{*}{ Current (A) } & \multirow[t]{2}{*}{$\operatorname{Bias}(\mathrm{V})$} & \multicolumn{2}{|c|}{ Pressure $(\mathrm{Pa})$} & \multicolumn{5}{|c|}{ Time (s) } \\
\hline & & & $\mathrm{Ar}$ & $\mathrm{N}_{2}$ & $1 \#$ & 2\# & $3 \#$ & $4 \#$ & $5 \#$ \\
\hline 330 & 0.4 & -50 & 0.5 & 0.25 & 131 & 157 & 196 & 262 & 393 \\
\hline
\end{tabular}



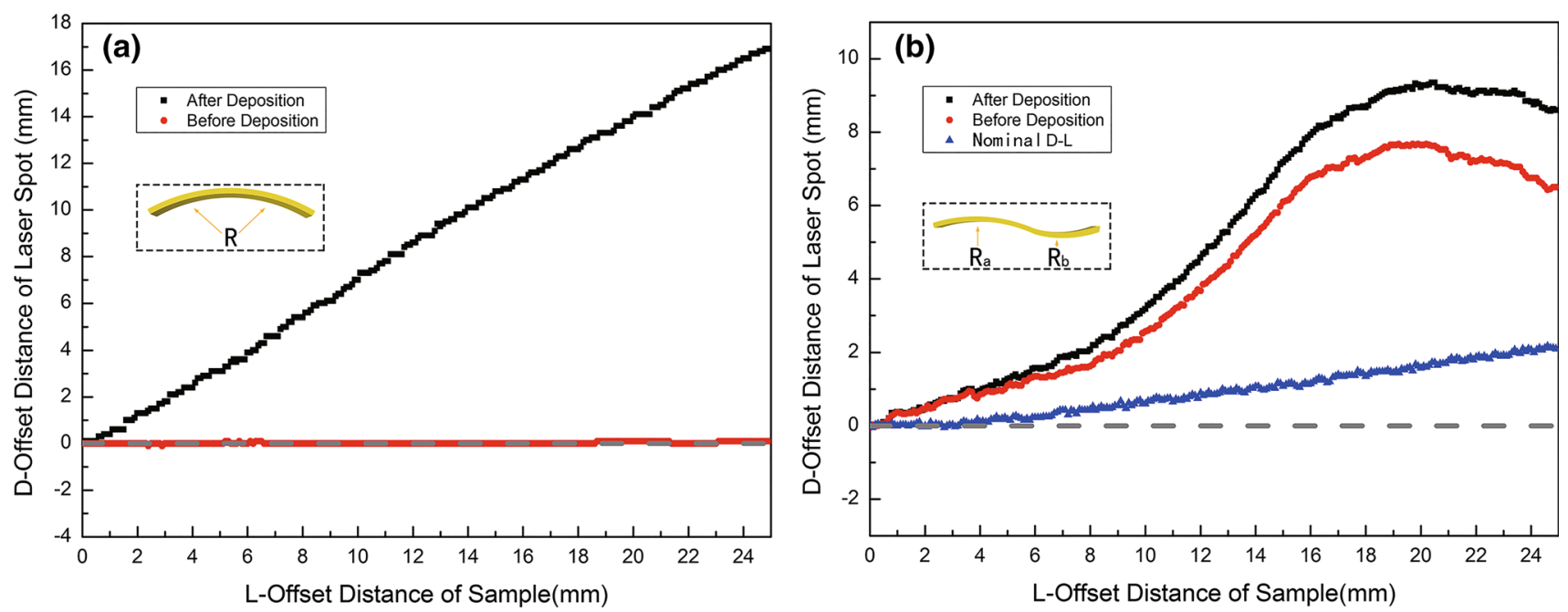

Fig. 1 Typical $D-L$ curves before/after film deposition for a silicon wafer, b stainless steel strip
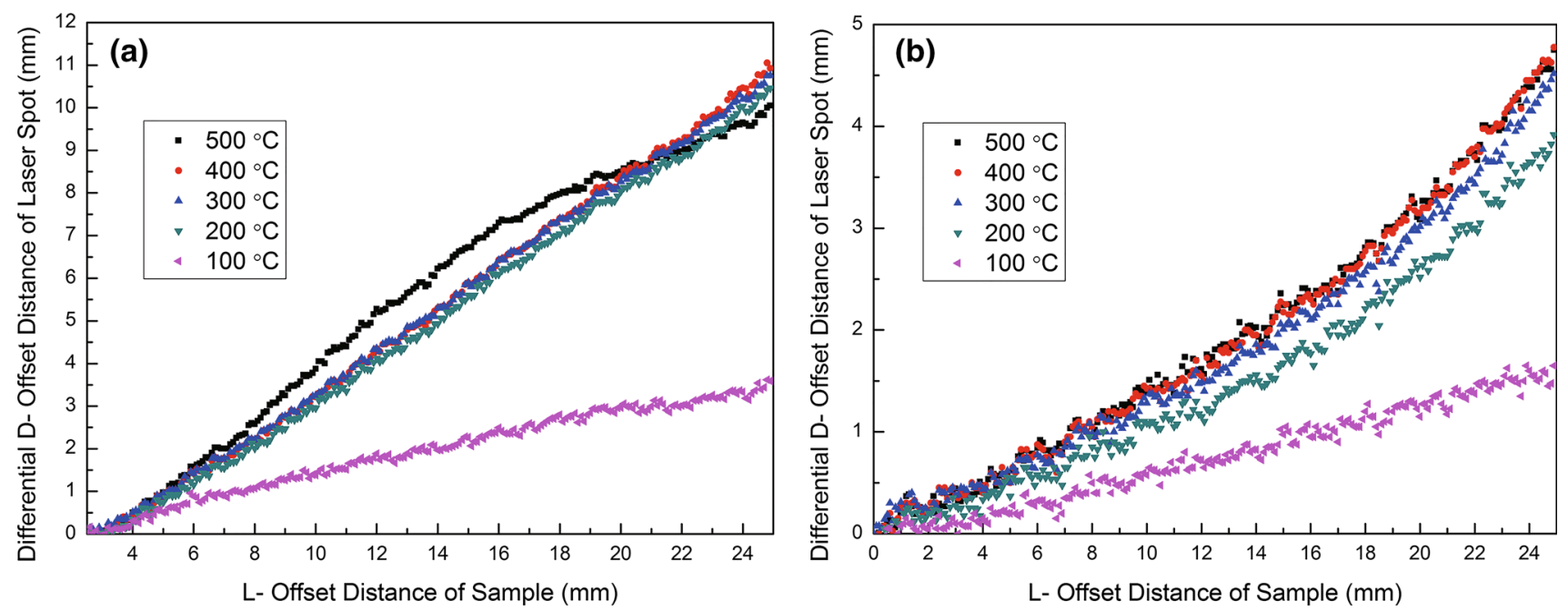

Fig. 2 Nominal $D-L$ curves for steel strip after heat treatment with thickness of a $0.5 \mathrm{~mm}, \mathbf{b} 0.8 \mathrm{~mm}$

$D-L$ curves are illustrated in Fig. 2. This difference is due to the fact that stress relief annealing is closely related to the sample volume, and the heat-treatment temperature or duration time in our work is still not enough to eliminate the defect in thick substrate. Figure 2 a shows that steel strip with thickness of $0.5 \mathrm{~mm}$ presents perfectly linear nominal $D-L$ curves, especially when annealed at temperature below $400{ }^{\circ} \mathrm{C}$. It indicates the stress relief because heat energy is uniform through the substrate. The nominal slop $K_{n}$ increased with annealing temperature, and a huge gap was found between 100 and $200{ }^{\circ} \mathrm{C}$, which implies that considerable amount of machining defect was vanished when the annealing temperature increased to $200{ }^{\circ} \mathrm{C}$. D$L$ curve saw a nonlinear trend when the temperature rose to $500{ }^{\circ} \mathrm{C}$; it is probably due to the unidentical stress relief temperature threshold for different parts of the substrates that provoked unequal deformation.
For stainless steel with thickness of $0.8 \mathrm{~mm}, D-L$ curves maintain better linear relationship than their thinner counterpart. Similar $K_{n}$ leap appeared at $200{ }^{\circ} \mathrm{C}$, and generally speaking, the differential $D-L$ curves become gentler as the substrate thickness increases.

As most of the $D-L$ curves are close to linear state, Eq. (6) is employed to analyze the heat-treatment stress relief, which was used to be misunderstood as part of the film stress. Figure 3 shows the simulation results of this stress error in films with different thicknesses and deposition temperatures on steel substrate with thickness of 0.5 and $0.8 \mathrm{~mm}$, respectively. It is obvious that higher deposition temperature and thinner film thickness cause larger stress error. Considering that the temperature increased by ion bombardment could be one hundred Celsius in some PVD process, it is somehow astonishing that even when the deposition temperature is at this level, the stress error for a 

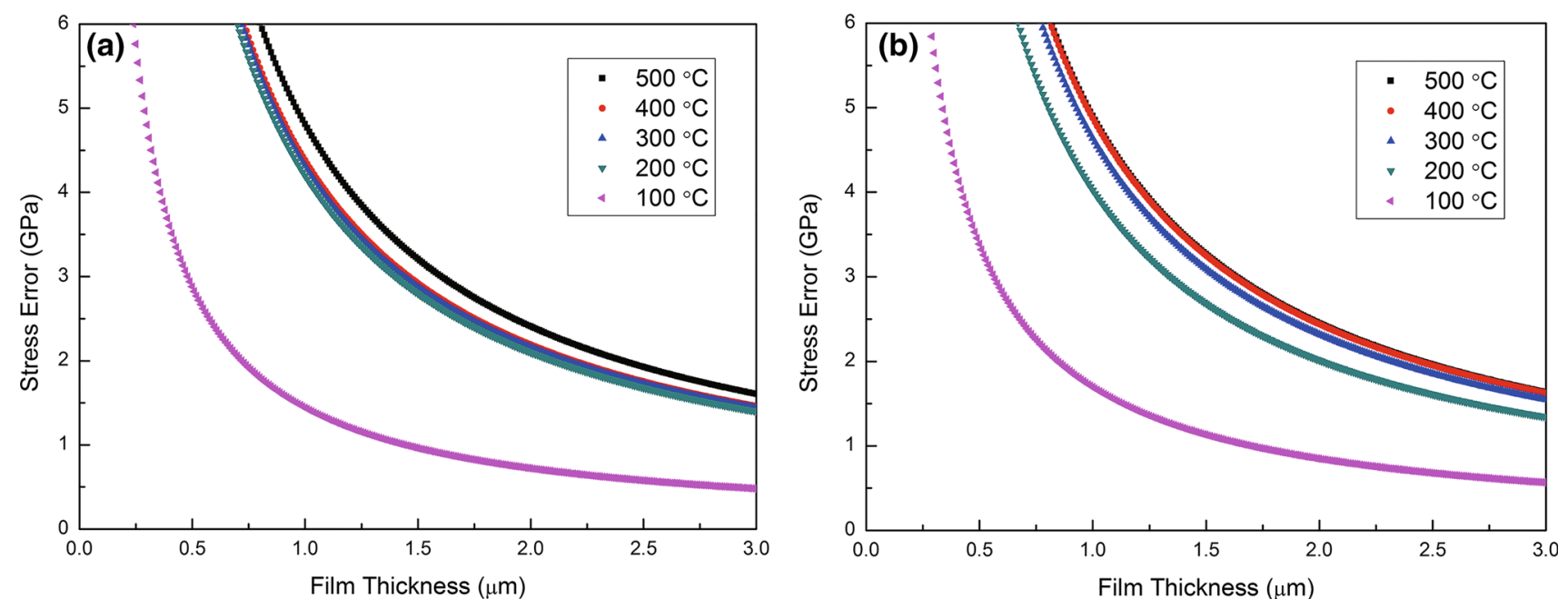

Fig. 3 Stress error in films with different thicknesses and deposition temperatures on steel substrate with thickness of a $0.5 \mathrm{~mm}, \mathbf{b} 0.8 \mathrm{~mm}$

3- $\mu \mathrm{m}$ film could be as large as $0.5 \mathrm{GPa}$, which is shown in the lower right part of Fig. 3, let alone some high temperature deposition process for thinner film. More seriously, according to the left part of Fig. 3a, b, for thin film whose thickness is only several $100 \mathrm{~nm}$, a trivial change in substrate curvature could result in fatal stress error, despite the low deposition temperature. Figure 4 shows that after 3-h annealing process at temperature of $500{ }^{\circ} \mathrm{C}$, the $D$ $L$ curves for steel strip with thickness of $0.8 \mathrm{~mm}$ remain the same in the following second round heating process which also lasts for $3 \mathrm{~h}$ for each temperature. In addition, substrates with thinner thickness of $0.3 \mathrm{~mm}$ that facilitates the measurement of small deflection presented the same $D$ $L$ curves evolution trend as thicker substrate in the second round heat treatment, which indicates that the stress error could be eliminated by this annealing process before film deposition.

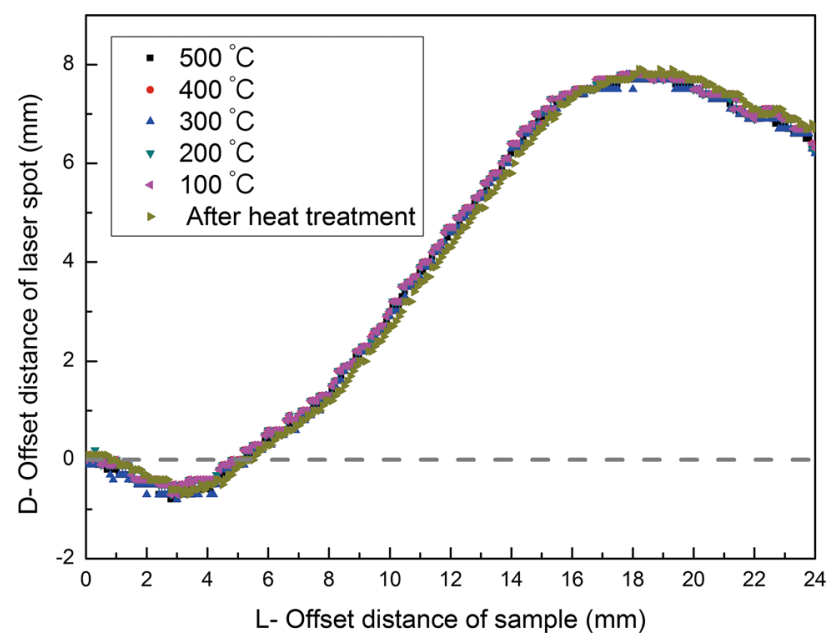

Fig. $4 D-L$ curves before and after the second round heat treatment for steel strip with thickness of $0.8 \mathrm{~mm}$
Therefore, we can arrived at the conclusion that heat treatment for stainless steel substrate before the curvature test is an indispensable, yet long neglected procedure in SCT film stress measurement method. The possible reasons for why this error has not been noted by now mainly lie in two aspects: (1) The choice of substrate for curvature measurements was often silicon wafer rather than steel. (2) Most of the researches [20,22] on stress of films deposited on tool substrate paid attention to films with thickness in excess of $1 \mu \mathrm{m}$, in which case, the annealing effect for substrate only brought in error that fell in seemingly reasonable range as shown in Fig. 3.

\subsection{Stress Analysis of the CrN Thin Films}

Figure 5a presents the $D-L$ curves for $3 \# \mathrm{CrN}$ thin film on $0.3-\mathrm{mm}$-thick steel substrate. The product of average stress and film thickness of this sample yielded the smallest steel substrate deflection in our experiment, and the clear linear nominal curve with slope $K_{n}$ calculated indicates the reliability and accuracy of the stress measurement method discussed above. Figure $5 \mathrm{~b}$ shows how average film stress evolves along the thickness direction on different substrates, and the film thickness, which is $110,132,164,220$, $330 \mathrm{~nm}$ for $1 \#-5 \#$, respectively, is derived from the crosssectional SEM images shown in the upper row of Fig. 6.

The stress in films deposited on silicon wafer decreased with increasing film thickness, yet always presents a tensile state. The evolution of stress in films on steel substrate first moved toward the tensile direction and peaked at $0.57 \mathrm{GPa}$ before the thickness reached $164 \mathrm{~nm}$, then shifted back to compressive state and increased as the film thickened.

If extrinsic stress provoked by phase transformation, precipitation, plastic or creep deformation or chemical reactions is left out of consideration, film stress should 

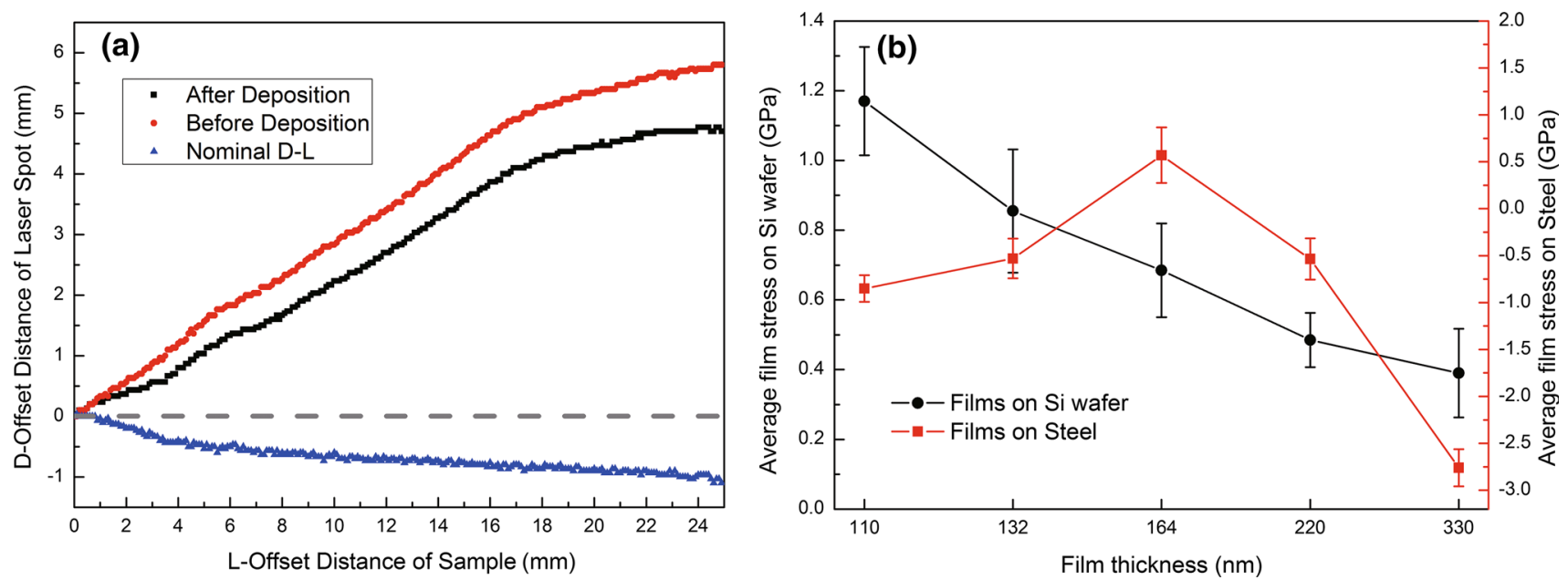

Fig. 5 Stress test results: a $D-L$ curves for sample $3 \#$ on steel substrate, b substrate dependent stress evolution with film thickness

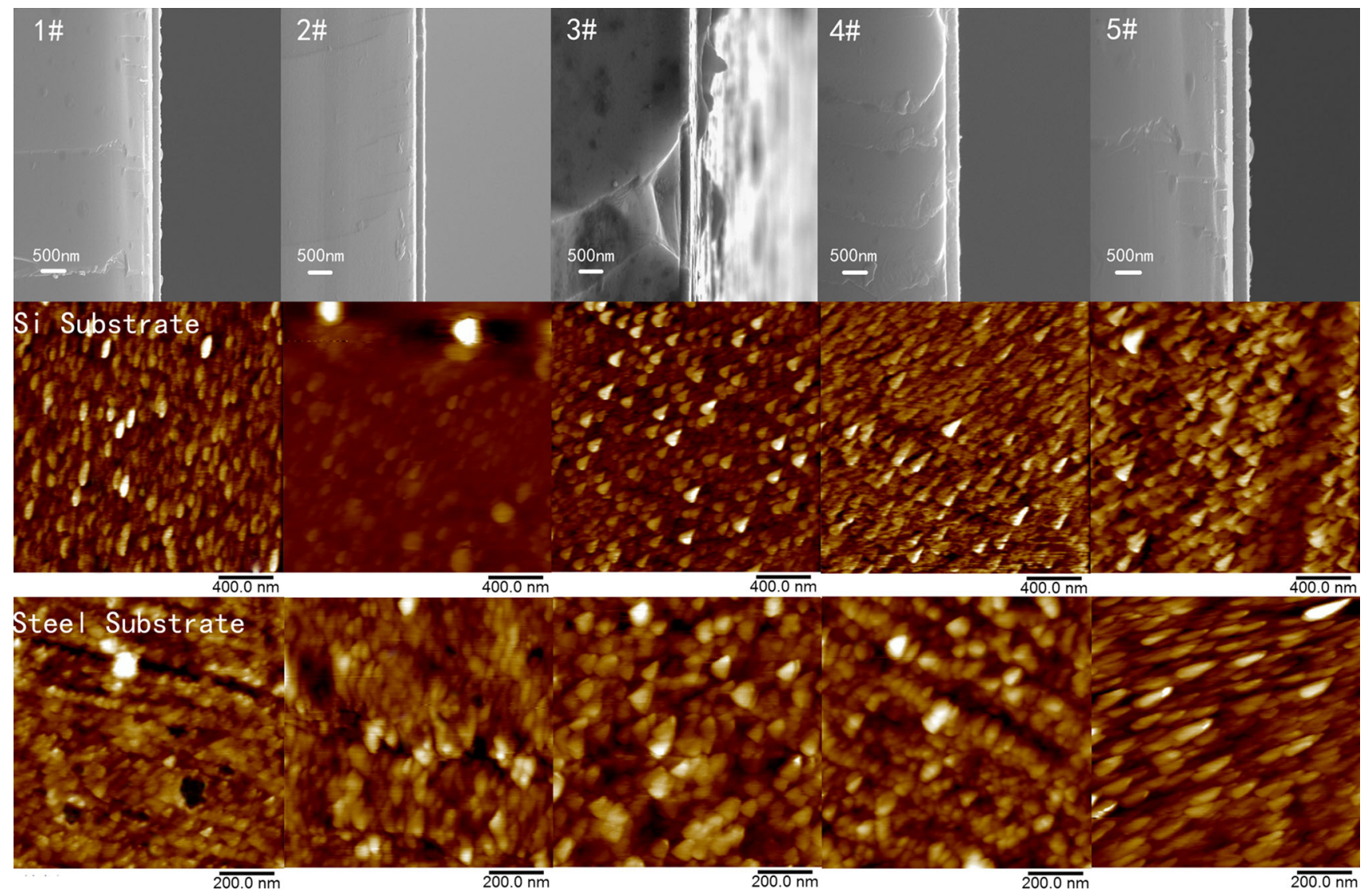

Fig. 6 Cross-sectional SEM images and AFM surface morphologies of 1\#-5\# CrN thin films on Si and steel substrates

consist of two parts, i.e., thermal and intrinsic stresses. Thermal stress depends on the thermal misfit led by the difference between film and substrate's CTE. Since CTE of the as-deposited film and substrates follows a relationship of $\alpha_{\mathrm{Si}}$ [18] $<\alpha_{\mathrm{CrN}}$ [8] $<\alpha_{\text {Steel }}$ [17], the thermal stress in the $\mathrm{CrN}$ thin films on $\mathrm{Si}$ wafer and steel should consequently be tensile and compressive, respectively. Daniel et al. [9] proved that the value of CrN's CTE tends to decrease as the film thickness increases, so the gap between $\alpha_{\mathrm{CrN}}$ and $\alpha_{\mathrm{Si}}$ would be wider for thicker films on steel, while the situation went the opposite way around on $\mathrm{Si}$ wafer. Both the increase and decrease in the CTE gaps led the film stress to 
a compressive direction on two substrates. Another origin of compressive stress is the ion bombardment effect $[23,24]$, the $50 \mathrm{~V}$ negative bias attracted ions and atoms with certain energy that incorporated into the films whose surface morphology is captured by AFM, as shown in the two lower rows of Fig. 6 . The surface of the thin films on $\mathrm{Si}$ wafer presents a dense state, as a result, the ions need to squeeze into the film, and spontaneously induce compressive stress. The increasing trend of compressive stress along thickness direction was also detected in $\mathrm{CrN}$ films deposited by Janssen et al. [8] and found in the first growth period of $\mathrm{CrN}$ films in experiment done by Chekour et al. [25], but in these studies, the compressive rather than the tensile stress existed in the films, which possessed an opposite sign to the stress in our work. This could be explained by the relatively high temperature and low bias voltage adopted in the deposition process. On the one hand, high temperature increased thermal tensile stress and enlarged the area of grain boundary which induced compressive stress according to the theory developed by Chason et al. [13] and thus decreased the compressive stress. On the other hand, low bias voltage weakened the ion bombardment effect and led to a less compact film structure with tensile stress.

For films on steel substrate, the porous surface not only weakened the increase in bias-induced compressive stress, but also shed light on the reason for the tensile stress increase in films deposited on steel before it thickened to $164 \mathrm{~nm}$. For films that grow by the Volmer-Weber mechanism, the impingement and coalescence of islands cause shrinkage of film volume and thus generate tensile stress $[26,27]$. This process was usually observed at the initial stage of film deposition on silicon, when the film thickness and grain width were several dozens of nanometers [28, 29], while in this work, the coalescence process that makes the film continuous and intact was postponed, because of the voids existing in the relatively thick film, increased tensile stress.

Another reason for the tensile stress generation is the grain boundary evolution. In Fig. 7, the cross-sectional scanning transmission electron microscopy (STEM) image of $5 \# \mathrm{CrN}$ thin film, with small grains scattering at the bottom of film and large grains crowding at the top, is consistent with the AFM images in Fig. 6. Since the grains are not symmetrical in shape, in Fig. 8, average grain circumference was adopted to characterize the grain boundaries. An increasing trend was clearly observed for both films on different substrates. Especially for the $\mathrm{CrN}$ thin film with thickness smaller than $164 \mathrm{~nm}$ on steel, the average circumference increased at an obviously faster rate than other stages of film deposition. Intrinsic compressive stress originates from the diffusion of excess sputtered adatoms to the grain boundaries [13], and grain growth

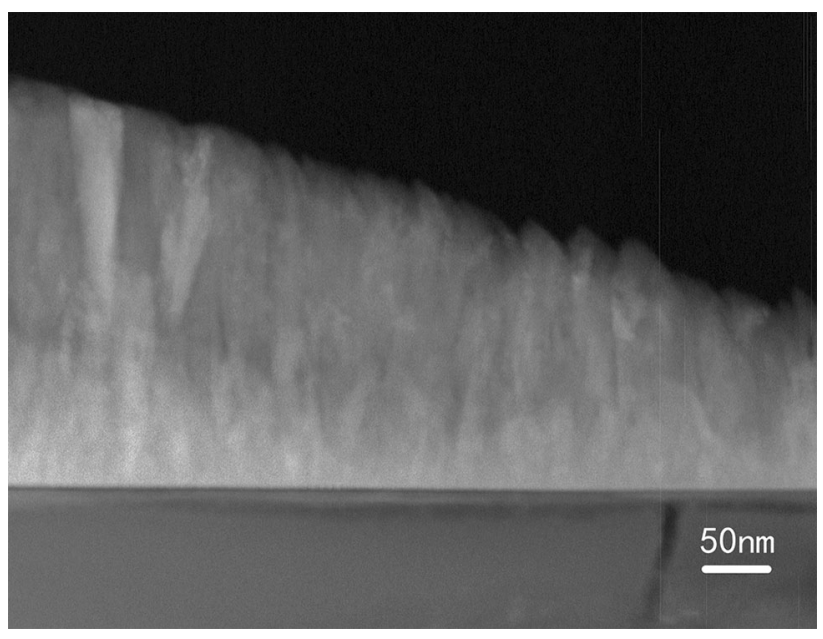

Fig. 7 Cross-sectional STEM image for the $\mathrm{CrN}$ thin film with thickness of $330 \mathrm{~nm}$

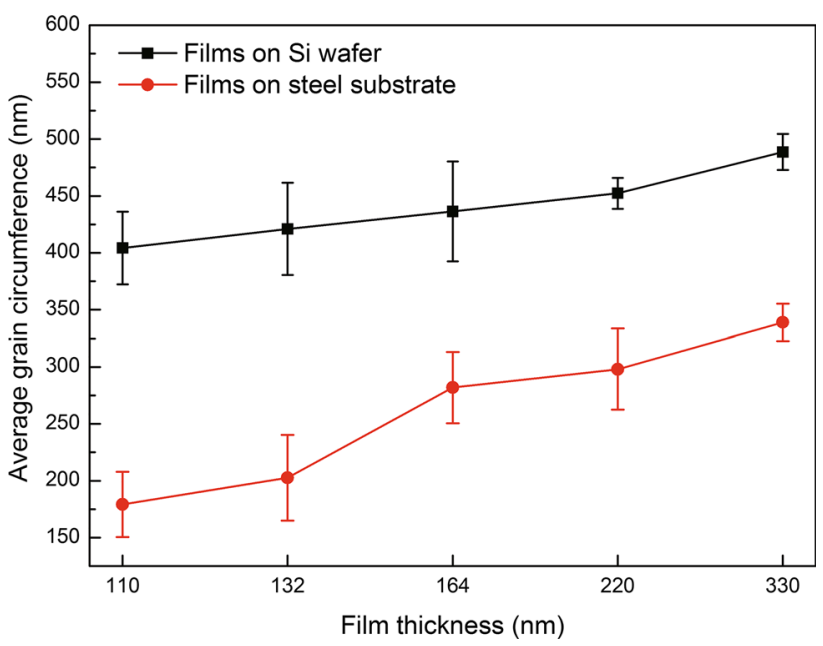

Fig. 8 Average surface grain circumference in the $\mathrm{CrN}$ thin films with different thicknesses

makes the bulk of the film more tensile or less compressive [30], so the grain coarsening provokes a decrease in compressive stress, i.e., an increase in tensile direction. Moreover, the grain size of films on steel substrate is nearly two times smaller than that of films on $\mathrm{Si}$ wafer, which supports the fact that the film on steel inclines to a more compressive state than its counterpart on $\mathrm{Si}$ wafer.

\section{Conclusions}

A SCT stress measurement method has been perfected, and the stress error brought in by substrate heating effect has been discussed. The stress in the $\mathrm{CrN}$ thin films with different thicknesses on steel substrate has been measured and studied in comparison with that on $\mathrm{Si}$ wafer. The most important results from this work include the following: 
1. The nominal curve method is reliable when applied to measure the stress in thin films on substrate with fluctuant surface. Equation (6) is derived to calculate the film stress. This result would facilitate the stress study of thin protective films on substrate in application.

2. Stress error brought in by the ignorance of substrate heating is proved to increase with the temperature and decrease with the film and substrate thickness. A stress error of $0.5 \mathrm{GPa}$ is given by the simulation for a general deposition condition.

3. Stress of the CrN thin films on steel and Si substrates is measured. A bell-shape evolution curve across the thickness direction is observed for films on steel, while a monotonic decreasing curve in tensile stress region is detected for the case of films on Si wafer.

4. It is shown that the $\mathrm{CrN}$ thin films with thickness less than $164 \mathrm{~nm}$ on steel have porous structure and faster grain coarsening speed than its counterpart on $\mathrm{Si}$ wafer, which contributes to the initial tensile stress generated in the $\mathrm{CrN}$ thin films on steel substrate. And the different film stress states on the two substrates are discussed to be originated from comprehensive reasons, including thermal misfit, bias effect, shrinkage of voids, and ion diffusion toward boundaries.

\section{References}

[1] B. Warcholinski, A. Gilewicz, Z. Kuklinski, P. Myslinski, Surf. Coat. Technol. 204, 2289 (2010)

[2] B. Bouaouina, A. Besnard, S.E. Abaidia, F. Haid, Appl. Surf. Sci. 395, 117 (2017)

[3] L. Cunha, M. Andritschky, K. Pischow, Z. Wang, Thin Solid Films 355, 465 (1999)

[4] X.M. He, N. Baker, B.A. Kehler, K.C. Walter, M. Nastasi, Y. Nakamura, J. Vac. Sci. Technol. A Vac. Surf. Films 18, 30 (2000)
[5] Y.H. Zhao, L. Xu, C.Q. Guo, W.J. Yang, G.Q. Lin, B.H. Yu, Acta Metall. Sin. (Engl. Lett.) 29, 546 (2016)

[6] C. Nouveau, M.A. Djouadi, O. Banakh, R. Sanjines, E. Levy, Thin Solid Films 398, 490 (2001)

[7] M.A. Djouadi, C. Nouveau, O. Banakh, R. Sanjines, F. Levy, G. Nouet, Surf. Coat. Technol. 151, 510 (2002)

[8] G. Janssen, F.D. Tichelaar, C.C.G. Visser, J. Appl. Phys. 100, 4 (2006)

[9] R. Daniel, K.J. Martinschitz, J. Keckes, C. Mitterer, Acta Mater. 58, 2621 (2010)

[10] C.V. Thompson, Annu. Rev. Mater. Sci. 30, 159 (2000)

[11] R. Abermann, Vacuum 41, 1279 (1990)

[12] R.W. Hoffman, Thin Solid Films 34, 185 (1976)

[13] E. Chason, B.W. Sheldon, L.B. Freund, J.A. Floro, S.J. Hearne, Phys. Rev. Lett. 88, 4 (2002)

[14] H. Oettel, R. Wiedemann, Surf. Coat. Technol. 76, 265 (1995)

[15] C.A. Klein, J. Appl. Phys. 88, 5487 (2000)

[16] G.G. Stoney, Proc. R. Soc. Lond. Ser. A Contain. Pap. Math. Phys. Character 82, 172 (1909)

[17] M. Spittel, T. Spittel, in ed. by H. Warlimont (Springer, Berlin Heidelberg, 2009)

[18] G.C.A.M. Janssen, M.M. Abdalla, F. van Keulen, B.R. Pujada, B. van Venrooy, Thin Solid Films 517, 1858 (2009)

[19] S.G. Malhotra, Z.U. Rek, S.M. Yalisove, J.C. Bilello, Thin Solid Films 301, 45 (1997)

[20] S.S. Zhao, H. Du, W.G. Hua, J. Gong, J.B. Li, C. Sun, J. Mater. Res. 22, 2659 (2007)

[21] S.S. Zhao, Y. Cheng, X.B. Zhang, K. Liang, J. Chin. J. Vac. Sci. Technol. 36, 98 (2016) (in Chinese)

[22] K.J. Martinschitz, R. Daniel, C. Mitterer, J. Keckes, Thin Solid Films 516, 1972 (2008)

[23] N.A. Marks, D.R. McKenzie, B.A. Pailthorpe, Phys. Rev. B 53, 4117 (1996)

[24] C.A. Davis, Thin Solid Films 226, 30 (1993)

[25] L. Chekour, C. Nouveau, A. Chala, C. Labidi, N. Rouag, M.A. Djouadi, Surf. Coat. Technol. 200, 241 (2005)

[26] H. Windischmann, Crit. Rev. Solid State Mater. Sci. 17, 547 (1992)

[27] J.A. Floro, E. Chason, R.C. Cammarata, D.J. Srolovitz, MRS Bull. 27, 19 (2002)

[28] S.C. Seel, C.V. Thompson, S.J. Hearne, J.A. Floro, J. Appl. Phys. 88, 7079 (2000)

[29] A.L. Shull, F. Spaepen, J. Appl. Phys. 80, 6243 (1996)

[30] H.Z. Yu, C.V. Thompson, Acta Mater. 67, 189 (2014) 